\title{
Cystometry-Postural Effects in Incontinent Women
}

$$
\text { E.P. }
$$

Department of Urology, Middlesex Hospital, London

\section{Key Words}

\section{Cystometry}

Pressure flow

Measurement

Request reprints from: Dr. E. P. Arnold, Department of Urology, Middlesex Hospital, London W1 (England)

An unstable bladder is one in which detrusor contractions occur in spite of the patient actively concentrating on holding his water. The aim of cystometry is to assess the stability or otherwise of the detrusor, and the part which any dysfunction may play in causing symptoms. The purpose of this paper is to discuss the influence of postural changes on cystometry in the full and partly full bladder.

Technique

The basic technique of combined video pressure/flow cystography used at the Middlesex Hospital has been described by Bates and Corney [1971]. A particular feature of the method is the estimation of the intrinsic detrusor bladder pressure by electrical subtraction of the abdominal pressure (rectal) from the total bladder pressure, with continuous recording.

The stability of the detrusor is tested by: (1) rapid filling supine; (2) standing with a full bladder; (3) repeat filling cystometry in the erect posture, and (4) coughing with a full bladder.

In normals, the rise in intrinsic pressure on filling is from $0-10 \mathrm{~cm} \mathrm{H20,} \mathrm{while} \mathrm{the} \mathrm{other} \mathrm{tests}$ above produce no rise.

\section{Postural Effects}

Standing with a full bladder. In normal patients no detrusor rise occurs. In a series of 109 incontinent women without outflow obstruction and without neurological disease, 32 had pure sphincter weakness (normal detrusor) and 77 had unstable bladders. In these 77, the first mani.186

\section{Arnold}

festation of instability was as follows: 32 contracted on supine filling; 20 contracted on standing; 5 contracted on erect filling, and 20 contracted on coughing.

If cystometry were only performed in the supine position, 58\% (45 of 77) of unstable bladders would remain undiagnosed.

Standing with a partly filled bladder. A small group of 15 patients was assessed, by standing and coughing with the bladder partly filled.

This demonstrates the importance of continuing bladder filling until it is uncomfortably full (mean filling volume $500 \mathrm{ml}$ ).

Comparison of supine and erect filling cystometry. This comparison was made between in 100 unselected patients: 87 had similar cystometry in both postures, 10 were normal supine, but unstable erect, and 3 were normal erect, but unstable supine. 


\section{Conclusions}

Postural changes do not affect the normal detrusor, but may help in the detection of detrusor instability which is an important factor in female incontinence. If routine supine cystometry alone is performed in investigating female incontinence, $58 \%$ of unstable bladders will remain undetected. The importance of adequate filling of the bladder in detecting instability has been demonstrated. Differences in filling cystometry in the supine and erect postures have been shown.

\section{References}

Bates, C. P. and Corney, C. E.: Synchronous cine-pressure-flow cystography: a method of routine urodynamic investigation. Brit. J. Radiol. 44: 44-50 (1971). 